\title{
A Prediction Model for Bacteremia and Transfer to Intensive Care in Pediatric and Adolescent Cancer Patients With Febrile Neutropenia
}

\section{Muayad Alali ( $\nabla$ muayad.alali20@gmail.com )}

University of Chicago Medicine

\section{Anoop Mayampurath}

The University of Chicago

\section{Yangyang Dai}

The University of Chicago

Allison H. Bartlett

University of Chicago Medicine

\section{Research Article}

Keywords: Febrile neutropenia (FN), diagnostic performance, FN episodes (FNEs), FN patients, TIC

Posted Date: December 14th, 2021

DOI: https://doi.org/10.21203/rs.3.rs-1120441/v1

License: (c) (i) This work is licensed under a Creative Commons Attribution 4.0 International License. Read Full License 


\section{Abstract}

\section{Objectives:}

Febrile neutropenia (FN) is a common condition in children receiving chemotherapy. Our goal in this study was to develop a model for predicting blood stream infection (BSI) and transfer to intensive care (TIC) at time of presentation in pediatric cancer patients with $\mathrm{FN}$.

\section{Methods:}

We conducted an observational cohort analysis of pediatric and adolescent cancer patients younger than 24 years admitted for fever and chemotherapy-induced neutropenia over a 7-year period. We excluded stem cell transplant recipients who developed $\mathrm{FN}$ after transplant and febrile non-neutropenic episodes. The primary outcome was onset of $\mathrm{BSI}$, as determined by positive blood culture within 7 days of onset of FN. The secondary outcome was transfer to intensive care (TIC) within 14 days of FN onset. Predictor variables include demographics, clinical, and laboratory measures on initial presentation for FN. Data were divided into independent derivation (2009-2015) and prospective validation (2015-2016) cohorts. Prediction models were built for both outcomes using logistic regression and random forest and compared with Hakim model. Performance was assessed using area under the receiver operating characteristic curve (AUC) metrics.

\section{Results:}

A total of $505 \mathrm{FN}$ episodes (FNEs) were identified in 230 patients. BSI was diagnosed in 106 (21\%) and TIC occurred in 56 (10.6\%) episodes. The most common oncologic diagnosis with FN was acute lymphoblastic leukemia (ALL), and the highest rate of BSI was in patients with AML. Patients who had BSI had higher maximum temperature, higher rates of prior BSI and higher incidence of hypotension compared with patients who did not have BSI. FN patients who were transferred to the intensive care (TIC) had higher temperature and higher incidence of hypotension at presentation compared to FN patients who didn't have TIC. We compared 3 models: (1) random forest (2) logistic regression and (3) Hakim model. The areas under the curve for BSI prediction were $(0.79,0.65$, and $0.64, \mathrm{P}<0.05)$ for models 1,2 , and 3 , respectively. And for TIC prediction were $(0.88,0.76$, and $0.65, \mathrm{P}<0.05)$ respectively. The random forest model demonstrated higher accuracy in predicting BSI and TIC and showed a negative predictive value (NPV) of 0.91 and 0.97 for BSI and TIC respectively at the best cutoff point as determined by Youden's Index. Likelihood ratios (LRs) (post-test probability) for RF model have potential utility of identifying low risk for $\mathrm{BSI}$ and TIC (0.24 and 0.12$)$ and high-risk patients (3.5 and 6.8) respectively.

\section{Conclusions:}

Our prediction model has a good diagnostic performance in clinical practices for both BSI and TIC in FN patients at the time of presentation. The model can be used to identify a group of individuals at low risk for BSI who may benefit from early discharge and reduce length of stay, also it can identify FN patients at high risk of complications who might benefit from more intensive therapies at presentation. 


\section{Introduction}

Febrile neutropenia (FN) is a common condition in children receiving chemotherapy and can be lifethreatening $(1,2)$. It would be useful to develop an evidence-based guideline and guidance based on an understanding of which clinical and tests most accurately predict patients at high risk of an adverse outcome who may prompt more aggressive management and intensive monitoring with a potential reduction in mortality rates also identify patients at low, or no, risk of serious clinical infection who may benefit from early discharge and less parenteral antibiotics during FN admission (3-5).

Several prediction rules based on clinical and laboratory parameters have been developed (6-9) for determining which FN patients are at risk for complications. However, these clinical decisions rules (CDRs) vary across populations and geographical locations, making it difficult to develop a single set of criteria to be used in clinical settings $(10,11)$. The available risk model studies have several limitations, including small study populations lacking independent validation, frequent missing values, and differences in the predictive factors considered. These CDRs have looked more to predict severe sepsis, bacteremia, documented infection as outcomes, however, CDRs for need critical care are limited(12).

To overcome the limitations of previous studies, efforts are under way to develop and validate risk models based on large studies in representative pediatric populations of patients receiving systemic chemotherapy. PICNICC (Predicting Infectious Complications in Children with Cancer) model was published as a mean of predicting complication in pediatric oncology patients (13). This study was limited by its reliance on studydefined microbiologically documented infection (MDI) as the endpoint outcome, rather than a more comprehensive, patient-centered assessment of adverse outcomes such as transfer to intensive care. Additionally, MDI represent a large spectrum of severity of infections, which could range from mild skin infection to severe invasive infection. Recent study found that PICNICC risk stratification schema performs poorly in adolescents/young adults (AYA) with cancer(14). There are a limited studies looked to prediction models in pediatric cancer patients with FN inside USA. Hakim et al developed a model (15) for predicting severe infections and adverse outcomes in FN based on a large sample size of pediatric cancer patients at St. Jude Children's Research Hospital.

The aims of this study are to examine relevant variables at the time of FN presentation and then to develop and validate a risk prediction model for bloodstream infection (BSI) and transfer to intensive care unit (TIC) in pediatric and adolescent cancer patients with FN.

\section{Methods}

\section{Setting and Study Population}

A retrospective cohort study was conducted at University of Chicago Medicine (UCM) Comer Children's Hospital, a 172-bed acute care hospital located on Chicago's south side that serves a diverse pediatric population. The medical center offers highly specialized cancer care, including stem cell transplant (SCT) (16). 
Study protocols were approved by the Clinical Trials Review Committee (CTRC) and the University of Chicago Institutional Review Board (IRB). We confirm all methods were carried out in accordance with relevant guidelines and regulations. The permission of informed consent is formally waived by approving committee. To identify appropriate patients for inclusion, the Clinical Research Data Warehouse, operated by the Center for Research Informatics, was queried for hospital admissions of patients 24 years of age or younger from March 2009 to December 2016 for discrete clinical and laboratory values as well as diagnosis codes using International Classification of Disease, 9th Revision, Clinical Modification (ICD-9CM) codes (ICD-10 after October 2015) to identify patients with FNE. Oncology patients were identified with ICD codes for malignancy or SCT diagnoses. Neutropenic patients were identified by ICD code for neutropenia OR absolute neutrophil count (ANC) <500. Febrile patients were identified by temperature $\geq 38.0^{\circ} \mathrm{C}\left(\geq 100.4^{\circ} \mathrm{F}\right)$ in a 24 -hr period (Figure 1$)$. A list of predictor variables is provided in Supplementary Table 2.

Manual electronic health record (EHR) review was conducted to verify that FN episodes were appropriate for inclusion based on the above characteristics. All episodes not meeting the above-mentioned criteria, including febrile non-neutropenic episodes, were excluded. SCT recipients who develop FN after transplant (Day \#0) were excluded. For patients with more than one admission for FN, each admission was counted as a separate episode. Data for all variables listed below were collected during manual EHR review.

\section{Data Collection}

Study data were collected by EHR review by a physician (MA,LP) and managed using REDCap (17). The risk prediction variables are a mixture of clinical findings, as well as basic laboratory studies, which are readily available at admission or at early reassessment, and which are convenient and easy to use across all other settings. Twenty clinical and laboratory variables at time of presentation were collected: patient demographics (age, gender, oncologic diagnosis, history of BSI and intravenous catheter-associated infection); clinical features (temperature, blood pressure, documented complaints [gastrointestinal symptoms, mucositis, upper respiratory symptoms and chills], and location at presentation); and laboratory data variables at presentation (white blood cell [WBC] count, absolute neutrophil count [ANC], absolute monocyte count [AMC], absolute lymphocyte count [ALC], platelet count, hemoglobin, duration of neutropenia before FN episode, and blood culture results.).

\section{Outcome and predictor variables}

The primary outcome of BSI was defined by a positive blood culture (within 7 days from the date of FN onset) with a pathogenic organism or with a contaminant (determined by the National Health Safety Network (NHSN) criteria for skin commensals) that the clinical team decided to treat as a pathogen (2). The secondary outcome of TIC was defined by transfer to ICU within 14 days from the date of FN onset. A list of predictor variables is provided in Supplementary Table 1. Fever was defined as a single oral temperature of $>38.3^{\circ} \mathrm{C}$ or temperature of $>38.0^{\circ} \mathrm{C}$ sustained over a 1 -h period or on more than one occasion in a 24 -hour period (2). Neutropenia was defined as ANC $<500 / \mathrm{mm}^{3}$. Hypotension was defined as a systolic blood pressure $<5$ th percentile for age and sex. Each FN episode was independently associated with outcomes 
using a variable indicating the number of prior $\mathrm{FN}$ episodes (categorized as 0,1 and $>1$ ) in order to control for recurrent episodes. We characterized underlying oncologic conditions in patients as belonging to one of four groups based on intensity of chemotherapy: (1) mixed leukemia and acute myeloid leukemia (AML); (2) acute lymphoblastic leukemia (ALL) and lymphoma (Hodgkin's and non-Hodgkin's); (3) neuroblastoma (NB); and (4) all other solid tumors.

\section{Patient management}

Institutional practice is to use ceftazidime as an initial empiric antimicrobial for $\mathrm{FN}$ patients with vancomycin \pm gentamicin added based on clinical presentation (i.e., concern for central venous catheter infection or septic shock). Cefepime was administered instead of ceftazidime for selected patients with high-risk FN such as acute myelogenous leukemia (AML). Empiric antifungal therapy (usually liposomal amphotericin B) was added if the patient remained febrile on day 5 of antibiotics and if neutropenia was expected to last longer than 5 to 7 days. We don't use routinely anti-bacterial prophylaxis; however, the small number of patients who on anti-bacterial prophylaxis were excluded. There were no major changes in FN management approach, diagnostics, and treatment during the study period.

\section{Prediction Model}

We utilized two machine learning techniques, logistic regression and random forest (RF), to predict BSI and TIC based on variables collected at time of FN presentation. While logistic regression models the association between the outcome and predictors in linear terms, RFs explore complex non-linear relationships between variables to further improve prediction accuracy. We split our dataset longitudinally into model derivation (years 2009-2014, $\mathrm{n}=343[68 \%]$ ) and independent prospective validation (years 2015$2016, n=162[32 \%]$ ) cohorts. Hyper-parameter optimization for random forests was performed on the derivation cohort using 5-fold cross validation. Final predictions were performed on the prospective validation dataset and the area under the receiver operating characteristic curve (AUC) was compared between the logistic regression model (LR), the RF model, and Hakim et al model (15) for both BSI and TIC. Variable importance plots were created to determine the variables most crucial to the prediction of each outcome using the RF model. Analyses were performed using R version 3.3 (R Project for Statistical Computing), with two-sided $\mathrm{P}<.05$ denoting statistical significance.

\section{Results}

\section{Study Population}

A total of $505 \mathrm{FN}$ episodes (FNEs) were identified in 230 patients. FN episodes during a unique admission ranged from 1-3 episodes with complete ANC recovery between these episodes.

The mean age was $11.0(S D=6.4)$ years and $47 \%$ were female (Table 1). Among 505 FNEs, $106(21 \%)$ developed BSI and among 230 patients, 77 (33\%) developed BSI (Table 1). The most frequent underlying diagnosis of patients with FNE was ALL/lymphoma. Rate of BSI were highest among patients with AML (Table 1) 
Table 1

Characteristics of FN episodes among pediatric cancer ( $\mathrm{N}=505)$

\begin{tabular}{|c|c|c|c|c|}
\hline & $\begin{array}{l}\text { All } \\
\text { Episodes } \\
(n=505)\end{array}$ & $\begin{array}{l}\text { FN episodes with positive } \\
\text { blood culture }(n=106)\end{array}$ & $\begin{array}{l}\text { FN episodes without } \\
\text { positive blood culture } \\
(n=399)\end{array}$ & $\begin{array}{l}\mathrm{P} \text { - } \\
\text { value }\end{array}$ \\
\hline Age, mean (SD) & $\begin{array}{l}11.08 \\
(6.4)\end{array}$ & $11.06(6.5)$ & $11.09(6.3)$ & 0.7 \\
\hline Female sex, n (\%) & $107(47)$ & $36(48)$ & $71(46)$ & 0.8 \\
\hline \multirow{2}{*}{$\begin{array}{l}\text { Cancer diagnosis, } \mathrm{n} \\
(\%)\end{array}$} & $218(43 \%)$ & $32(30 \%)$ & $186(46 \%)$ & 0.09 \\
\hline & $89(18 \%)$ & 37 (35\%) & $52(13 \%)$ & $<0.01$ \\
\hline ALL/IYIIPIIOIId & $69(14 \%)$ & $22(21 \%)$ & 47 (13\%) & 0.08 \\
\hline $\begin{array}{l}\text { AML/mixed } \\
\text { leukemia }\end{array}$ & $129(25 \%)$ & $15(14 \%)$ & $114(28 \%)$ & 0.07 \\
\hline \multicolumn{5}{|l|}{ Neuroblastoma } \\
\hline \multicolumn{5}{|l|}{ Other solid tumors } \\
\hline \multicolumn{5}{|l|}{$\begin{array}{l}\text { Neutropenia >7 } \\
\text { days prior FN, } n \text { (\%) }\end{array}$} \\
\hline Yes & 346 (68) & $69(65)$ & 277 (69) & 0.8 \\
\hline No & $105(21)$ & $33(31)$ & $72(18)$ & \\
\hline Unknown & $54(11)$ & $4(4)$ & $50(13)$ & \\
\hline \multicolumn{5}{|l|}{ Prior BSI, n (\%) } \\
\hline Yes & $133(26)$ & $44(42)^{\star}$ & $89(22)$ & $<0.01$ \\
\hline No & $372(74)$ & $62(58)$ & 310 (78) & \\
\hline \multicolumn{5}{|l|}{$\begin{array}{l}\text { GI symptoms }{ }^{\star \star \star} n \\
(\%)\end{array}$} \\
\hline Yes & $173(34)$ & $36(34)$ & $137(34)$ & 0.9 \\
\hline No & $332(66)$ & $70(64)$ & $263(66)$ & \\
\hline \multicolumn{5}{|l|}{ Mucositis n (\%) } \\
\hline Yes & $111(22)$ & $23(21)$ & $88(22)$ & 0.9 \\
\hline No & 394 (78) & $83(79)$ & 312 (78) & \\
\hline
\end{tabular}

${ }^{*} \mathrm{P}<0.05$ compared to patient admission that did not develop positive blood culture

** VURI viral upper respiratory infection documented by RVP

***includes subjective symptoms such as vomiting, diarrhea, or abdomen pain 


\begin{tabular}{|c|c|c|c|c|}
\hline & $\begin{array}{l}\text { All } \\
\text { Episodes } \\
(n=505)\end{array}$ & $\begin{array}{l}\text { FN episodes with positive } \\
\text { blood culture }(n=106)\end{array}$ & $\begin{array}{l}\text { FN episodes without } \\
\text { positive blood culture } \\
(n=399)\end{array}$ & $\begin{array}{l}\mathrm{P} \text { - } \\
\text { value }\end{array}$ \\
\hline \multicolumn{5}{|l|}{ VURI ** } \\
\hline Yes & $167(33)$ & $19(18)^{\star}$ & $148(37)$ & 0.03 \\
\hline No & $268(53)$ & $72(68)$ & $196(49)$ & \\
\hline Unknown & $70(14)$ & $28(26)$ & $58(14)$ & \\
\hline \multicolumn{5}{|l|}{ Chills } \\
\hline Yes & $28(6)$ & $13(12)^{\star}$ & $15(4)$ & 0.02 \\
\hline No & $477(94)$ & $93(88)$ & $384(96)$ & \\
\hline \multicolumn{5}{|l|}{ Hypotension } \\
\hline Yes & $89(18)$ & $39(36)^{\star}$ & $50(12.5)$ & $<0.01$ \\
\hline No & $416(82)$ & $75(70)$ & $341(86)$ & \\
\hline \multicolumn{5}{|l|}{$\begin{array}{l}\text { Temperature height } \\
\text { at presentation }\end{array}$} \\
\hline$>=39$ & $122(25)$ & $41(39) \star$ & $81(20)$ & $<0.01$ \\
\hline$<39$ & $383(75)$ & $65(61)$ & $318(80)$ & \\
\hline \multicolumn{5}{|l|}{$\begin{array}{l}\text { Chemotherapy in } \\
\text { last } 2 \text { weeks }\end{array}$} \\
\hline Yes & $282(76)$ & 78(74) & $303(76)$ & 0.7 \\
\hline No & 124(34) & $28(26)$ & $96(24)$ & \\
\hline \multicolumn{5}{|l|}{$\begin{array}{l}\text { Inpatient (location } \\
\text { FN) }\end{array}$} \\
\hline Yes & $85(17)$ & $27(25)^{\star}$ & $59(15)$ & 0.02 \\
\hline No & $420(83)$ & $79(75)$ & 341 (85) & \\
\hline \multicolumn{5}{|l|}{$\mathrm{Hx} F \mathrm{~F}>1$} \\
\hline $\begin{array}{l}\text { Yes ( } 2,3 \text { or } 4 \\
\text { episodes) }\end{array}$ & $311(61)$ & $81(76)^{*}$ & $230(57)$ & 0.01 \\
\hline No (0 or 1 episode) & 194 (39) & $29(27)$ & $165(41)$ & \\
\hline
\end{tabular}

*P<0.05 compared to patient admission that did not develop positive blood culture
$\star *$ VURI viral upper respiratory infection documented by RVP
$\star * \star$ includes subjective symptoms such as vomiting, diarrhea, or abdomen pain




\begin{tabular}{|c|c|c|c|c|}
\hline & $\begin{array}{l}\text { All } \\
\text { Episodes } \\
(n=505)\end{array}$ & $\begin{array}{l}\text { FN episodes with positive } \\
\text { blood culture }(n=106)\end{array}$ & $\begin{array}{l}\text { FN episodes without } \\
\text { positive blood culture } \\
(n=399)\end{array}$ & $\begin{array}{l}\mathrm{P}- \\
\text { value }\end{array}$ \\
\hline \multicolumn{5}{|l|}{ ALC, n (\%) } \\
\hline$<300$ & 156 (31) & $44(41)^{\star}$ & $112(28)$ & 0.012 \\
\hline$>300$ & 342 (68) & $61(58)$ & $281(70)$ & \\
\hline Unknown & $7(1)$ & $1(1)$ & $6(2)$ & \\
\hline \multicolumn{5}{|l|}{ ANC, n (\%) } \\
\hline$<100$ & 362 (72) & 78 (74) & $284(71)$ & 0.713 \\
\hline$>100$ & $143(28)$ & $28(26)$ & $115(29)$ & \\
\hline \multicolumn{5}{|l|}{ AMC n (\%) } \\
\hline$<100$ & 389 (77) & $84(79)$ & $304(76)$ & 0.68 \\
\hline$>100$ & $105(21)$ & $19(18)$ & $86(22)$ & \\
\hline Unknown & $12(2)$ & $3(3)$ & $9(2)$ & \\
\hline \multicolumn{5}{|l|}{ Platelet } \\
\hline$<50$ & 308 (61) & $226(57)^{\star}$ & $82(77)$ & 0.01 \\
\hline$>=50$ & 197 (39) & $173(43)$ & $24(23)$ & \\
\hline \multicolumn{5}{|l|}{$\mathrm{Hb}<7$} \\
\hline Yes & $103(20)$ & $29(27)$ & $74(18)$ & 0.07 \\
\hline No & $402(80)$ & 77 (73) & 325 (82) & \\
\hline \multicolumn{5}{|l|}{ Prior GCSF } \\
\hline Yes & $66(13)$ & $57(14)$ & $9(9)$ & 0.158 \\
\hline No & 439 (87) & $342(86)$ & $97(91)$ & \\
\hline $\begin{array}{l}\text { Admitted to the } \\
\text { PICU, n (\%) }\end{array}$ & $54(11)$ & $24(23)^{\star}$ & $30(8)$ & $<0.01$ \\
\hline \multicolumn{5}{|c|}{${ }^{*} \mathrm{P}<0.05$ compared to patient admission that did not develop positive blood culture } \\
\hline \multicolumn{5}{|c|}{ 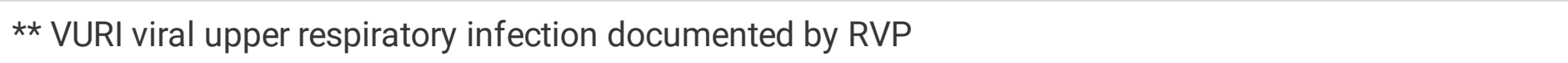 } \\
\hline$\star \star \star$ includes subje & ymptoms & ch as vomiting, diarrhea, o & domen pain & \\
\hline
\end{tabular}

In bivariable analysis, FNEs that resulted in BSI, compared with FNEs that did not result in BSI, were more likely to have; underlying diagnosis of $A M L$ (odds ratio $[O R]=2.8,95 \% \mathrm{Cl} 1.25-6.36$ ), history of a prior $\mathrm{BSI}$ $(\mathrm{OR}=2.4,95 \% \mathrm{Cl} 1.12-5.35)$, thrombocytopenia $<50(\mathrm{OR}=2.1,95 \% \mathrm{Cl} 1.13-5.72), \mathrm{ALC}<300 / \mathrm{mm}^{3}$ at time of 
presentation ( $\mathrm{OR}=1.8,95 \% \mathrm{Cl}$ 0.88-4.83), hypotension ( $\mathrm{OR}=4.15,95 \% \mathrm{Cl} 2.30$ to 8.04), higher height of fever ( $\mathrm{OR}=4.69,95 \% \mathrm{Cl} 2.59$ to 7.16$)$, chills $(\mathrm{OR}=2.22,95 \% \mathrm{Cl} 1.40$ to 4.56$)$ at time of presentation, being inpatient than outpatient ( $\mathrm{OR}=1.7,95 \% \mathrm{Cl} 0.9-3.93)$, and less likely to have VURI (OR=0.42, 95\% $\mathrm{Cl}, 0.20$ to 0.93$)$ (Table 1). A total of 115 organisms were recovered during 106 episodes of BSI in 77 patients. Gram-positive bacteremia was detected in 65/106 (56.5\%) and Gram-negative bacteremia was detected in 46/106 (43.3\%) episodes. Polymicrobial bacteremia was detected in 7/106 (6.6\%).

FNEs from 2009-2014 ( $\mathrm{N}=343$ ) were used to derive the model for BSI and TIC, while FNEs from 2015-2016 $(N=162)$ were used for validation. We report the rate of the variables and outcomes in each of derivation and validation group (see Table2). 
Table 2

Characteristics variables and outcomes in FNEs among derivation and validation cohorts $(\mathrm{N}=505)$

\begin{tabular}{|c|c|c|c|}
\hline & $\begin{array}{l}\text { All Episodes } \\
(n=505) \mathrm{N} \\
(\%)\end{array}$ & $\begin{array}{l}\text { Derivation cohort } \\
(2009-2014, n=343 \\
[68 \%])\end{array}$ & $\begin{array}{l}\text { Validation cohort } \\
(2015-2016), \mathrm{n}= \\
162[32 \%])\end{array}$ \\
\hline Age, mean (SD) & $11.08(6.4)$ & $10.16(5.8)$ & $12.59(6.8)$ \\
\hline Female sex & $107(47)$ & $159(46)$ & $69(42)$ \\
\hline Cancer diagnosis & $218(43 \%)$ & 149 (44\%) & $69(41 \%)$ \\
\hline ALL/lymphoma & $89(18 \%)$ & $54(16 \%)$ & $35(21 \%)$ \\
\hline AML/mixed leukemia & $69(14 \%)$ & $51(15 \%)$ & $18(11 \%)$ \\
\hline Neuroblastoma & $129(25 \%)$ & $89(26 \%)$ & $40(24 \%)$ \\
\hline \multicolumn{4}{|l|}{ Other solid tumors } \\
\hline Neutropenia $>7$ days prior $\mathrm{FN}$ & 346 (68) & $221(70)$ & $125(75)$ \\
\hline Prior BSI in last 12 months & $133(26)$ & $83(24)$ & $50(30)$ \\
\hline GI symptoms n (\%) & $173(34)$ & $125(36)$ & $48(30)$ \\
\hline Mucositis n (\%) & $111(22)$ & $81(24)$ & $30(18)$ \\
\hline VURI & $167(33)$ & 109(31) & $58(35)$ \\
\hline Chills & $28(6)$ & $18(5)$ & $10(6)$ \\
\hline Hypotension & $89(18)$ & $68(20)$ & $21(13)$ \\
\hline $\begin{array}{l}\text { Temperature }>39 \text { at } \\
\text { presentation }\end{array}$ & $122(25)$ & $91(26)$ & $31(19)$ \\
\hline Chemotherapy in last 2 weeks & $282(76)$ & $198(57)$ & $84(52)$ \\
\hline Inpatient (location FN) & $85(17)$ & $52(15)$ & $33(20)$ \\
\hline $\mathrm{Hx} F \mathrm{~N}>1$ & $311(61)$ & $201(58)$ & $110(68)$ \\
\hline ALC <300, n (\%) & $156(31)$ & $96(28)$ & $60(37)$ \\
\hline ANC<100, n (\%) & $362(72)$ & $239(70)$ & $123(76)$ \\
\hline AMC < $100 \mathrm{n}(\%)$ & 389 (77) & $251(74)$ & 138 (85) \\
\hline Platelet $<50$ & 308 (61) & 203 (59) & 105 (64) \\
\hline $\mathrm{Hb}<7$ & $103(20)$ & $77(22)$ & $26(16)$ \\
\hline Prior GCSF & $66(13)$ & $41(12)$ & $25(15)$ \\
\hline BSI & $106(21)$ & $66(19)$ & $40(24)$ \\
\hline
\end{tabular}




\begin{tabular}{|llll|}
\hline & $\begin{array}{l}\text { All Episodes } \\
\left(\begin{array}{l}n=505) \\
(\%)\end{array}\right.\end{array}$ & $\begin{array}{l}\text { Derivation cohort } \\
(\mathbf{2 0 0 9 - 2 0 1 4 , ~} \mathrm{n}=343 \\
[68 \%])\end{array}$ & $\begin{array}{l}\text { Validation cohort } \\
(\mathbf{2 0 1 5 - 2 0 1 6 ) , ~} \mathrm{n}= \\
\mathbf{1 6 2 [ 3 2 \% ] )}\end{array}$ \\
\hline Admitted to the PICU, $\mathrm{n}(\%)$ & $54(11)$ & $35(10)$ & $19(12)$ \\
\hline
\end{tabular}

\section{Model Performance}

AUCs and statical performance for different prediction models using the prospective validation cohort are shown in Table 3. The logistic regression model (LR) performed similarly to the Hakim model in predicting BSI (LR AUC 0.65 vs. Hakim AUC 0.66), whereas the RF model predicted BSI much more accurately than the Hakim model (RF AUC 0.79 vs. Hakim AUC 0.66, P < 0.05) (Table3) (Figure 4). The RF model also performed best at predicting 14-day TIC as compared to the LR model and the Hakim Model (RF AUC 0.88 vs LR AUC $0.76, P<0.05)$ and (RF AUC 0.88 vs Hakim AUC 0.65, $P<0.05)$.

Table 3

Statical Performance of 3 prediction models for BSI and TIC

\begin{tabular}{|c|c|c|c|c|c|c|c|c|}
\hline & Threshold & $\begin{array}{l}\text { Sensitivity } \\
\%( \pm \\
95 \% \mathrm{Cl})\end{array}$ & $\begin{array}{l}\text { Specificity } \\
\%( \pm \\
95 \% \mathrm{Cl})\end{array}$ & $\begin{array}{l}\text { PPV \% } \\
( \pm \pm \\
95 \% \mathrm{Cl})\end{array}$ & $\begin{array}{l}\text { NPV \% } \\
( \pm \pm \\
95 \% \mathrm{Cl})\end{array}$ & $\begin{array}{l}\text { LR+ } \\
\text { (HR) }\end{array}$ & $\begin{array}{l}\text { LR- } \\
\text { (LR) }\end{array}$ & $\begin{array}{l}\text { AUC } \\
(95 \% \\
\text { Cl) }\end{array}$ \\
\hline \multicolumn{9}{|l|}{ BSI } \\
\hline $\begin{array}{l}\text { Random } \\
\text { Forest }\end{array}$ & 0.056 & $81(68-92)^{*}$ & $77(65-89)$ * & $\begin{array}{l}51(43- \\
66)\end{array}$ & $\begin{array}{l}91(82- \\
98)^{\star}\end{array}$ & $3.5^{\star}$ & 0.24 & $\begin{array}{l}0.79 \\
(0.71- \\
0.85)^{\star}\end{array}$ \\
\hline $\begin{array}{l}\text { Logistic } \\
\text { Regression }\end{array}$ & 0.06 & $73(63-84)$ & $70(61-80)$ & $\begin{array}{l}46(55- \\
38)\end{array}$ & $\begin{array}{l}86(78- \\
90)\end{array}$ & 2.4 & 0.38 & $\begin{array}{l}0.65 \\
(0.53, \\
0.76)\end{array}$ \\
\hline Hakim & - & $68(62-74)$ & $62(54-71)$ & $\begin{array}{l}40(36- \\
48)\end{array}$ & $\begin{array}{l}79(71- \\
87)\end{array}$ & 1.7 & 0.61 & $\begin{array}{l}0.66 \\
(0.56, \\
0.77)\end{array}$ \\
\hline \multicolumn{9}{|l|}{ TIC } \\
\hline $\begin{array}{l}\text { Random } \\
\text { Forest }\end{array}$ & 0.049 & $89(78-97)^{\star}$ & $87(80-95) *$ & $\begin{array}{l}56(47- \\
64)\end{array}$ & $\begin{array}{l}97(92- \\
99)^{\star}\end{array}$ & $6.8^{*}$ & $0.12^{\star}$ & $\begin{array}{l}0.88 \\
(0.76, \\
0.99)^{\star}\end{array}$ \\
\hline $\begin{array}{l}\text { Logistic } \\
\text { Regression }\end{array}$ & 0.053 & $81(71-90)$ & $83(77-88)$ & $\begin{array}{l}46(39- \\
53)\end{array}$ & $\begin{array}{l}92(85- \\
97)\end{array}$ & 4.7 & 0.22 & $\begin{array}{l}0.76 \\
(0.60, \\
0.92)\end{array}$ \\
\hline Hakim & - & $71(62-80)$ & 72 (68-79) & $\begin{array}{l}35(27- \\
44)\end{array}$ & $\begin{array}{l}80(73- \\
86)\end{array}$ & 2.5 & 0.4 & $\begin{array}{l}0.65 \\
(0.50, \\
0.80)\end{array}$ \\
\hline
\end{tabular}

For each outcome, a likelihood ratio (LR) was calculated with 95\% credibility (post-test probability) to assess a probability of BSI or TIC and potential utility of prediction model in clinical practice. As the 
quantitative value of a calculated LR is further away from 1 in either direction, there is increasing utility of prediction tool to point toward, or away from outcomes. The higher positive LR, the more model ability in identifying high risk FN patients, and the lower negative LR, the more ability to identifying low risk patients. RF model has higher LR+ compared with Hakim et al in predicting high risk for BSI $(3.5$ vs $1.7, \mathrm{P}<0.05)$ and TIC (6.8 vs $2.6, P<0.05)$, also in predicting low risk for both BSI and TIC ( 0.24 vs 6$)$, and (0.12 vs 0.4$)$ respectively. Other statical performance for each model (Table3).

Because the RF utilizes a decision-tree type approach, the location of each variable across all trees is an approximate measure of the importance of that variable towards predicting the outcome. Figure 2 depicts the 10 variables most important to predicting BSI. Of these, temperature, low blood pressure, prior positive blood culture, and AML as underlying diagnosis are the most important variables used by the RF to predict positive blood culture. Temperature and low blood pressure are highly important in the RF model for predicting TIC (Figure 3).

\section{Discussion}

In this study, we derived and validated a prediction model for BSI and transfer to ICU in a large, diverse population of children with cancer that demonstrated better performance than previously published methods. Independent risk factors for BSI and TIC included high temperature and low blood pressure on admission. The use of such risk factors to identify the patients who are at greatest risk for BSI and risk for TIC could help providers to the appropriate level of care.

There is currently no single risk stratification system is in widespread use in pediatric practice and there are considerable variations in practice. A simple, reliable, and safe risk stratification system will have potential to significantly reduce hospitalization rates without increasing overall mortality.

Several previous investigations of pediatric cancer patients with $\mathrm{FN}$ have identified different hematologic laboratory results $(6,7,9,15,18)$ (e.g., ANC, platelet count, or absolute monocyte count), clinical factors related to a patient's underlying cancer (e.g., diagnosis of AML or the presence of uncontrolled relapsed disease) and vital sign abnormalities (e.g., fever, hypotension) $(8,21,22,23$,$) as risk factors for BSI, MDI and$ adverse outcomes

Most previous studies have treated temperature as a dichotomous variable (temperature $>39$ or $<39$ degrees) $(8,12,15,19)$. In our study, including maximal temperature as a continuous variable increased model performance in predicting BSI and TIC. We also identified hypotension as an independent risk for both BSI and TIC, like other studies $(12,20)$.

We identified prior BSI, regardless underlying diagnosis, as an additional variable important to predicting BSI. Subsequent BSI did not represent inadequate treatment or relapse of initial infections since subsequent BSI were caused by different pathogens than the index BSI. This finding was still significant whether the central line was retained or removed. When we excluded BSI caused by the common skin contaminant Coagulase-negative staphylococci (CoNS), the prediction model performance remained the same. 
Similar to previous studies, we found that AML patients with FN are more likely to develop BSI compared with patients with other underlying diagnoses. This is not surprising since patients with AML receive more intensive chemotherapeutic regimens (i.e., Cytarbine containing regimen) than do other oncologic patients, leading to longer durations of neutropenia and thus a higher risk of infectious complications $(21,22)$.

Previous studies have investigated the impact of $\operatorname{AMC}(9,10,12)$ in predicting BSI. Phillips et al.(10), 2010 review evidence on the ability of existing clinical decision rules to risk stratify children and young people presenting with FN including nearly 8,000 episodes of FN and of described outcomes need for critical care, significant bacterial infection or bacteraemia. Most studies could not be pooled as they differed too much from one another in terms of rules, outcomes, locations and populations. However, data from multiple studies validated two existing rules (Rackoff rule(7) with an outcome of 'bacteraemia' and the Santolaya rule(9) with an outcome 'invasive bacterial infection'). likelihood ratio (LR+) was calculated with $95 \%$ confidence intervals 3.4, and 2.8 respectively, these rules conclude patients with AMC $>100 \mathrm{~mm}^{3}$ at time of presentation are low risk. In our study, AMC, as single variable, was poor predictive of either BSI or transfer to ICU in multi-regression analysis.

Strengths of our study include the relatively large patient population and number of events of the outcomes of interest (BSI and ICU transfer). We performed simultaneous assessment of potential risk factors allowing for the identification of independent factors predictive of BSI or ICU transfer, each of which we evaluated separately. Data pulled from our data warehouse was supplemented by manual review of the electronic medical record. Our prediction model provides a robust method of determining pediatric cancer patients with high risk of BSI and transfer to ICU. The model's performance is better than other published models.

The current study has several limitations. First, it is a retrospective analysis at a single academic medical center and the results may not be generalizable to other institutions with different practices of antimicrobial prophylaxis and different empiric management of neutropenic fevers. Because our study was retrospective, we are limited in our ability to collect accurate objective clinical variables from the medical record such as mucositis, chills, and upper respiratory tract symptoms. To decrease observer bias, risk factors and outcomes of interest were recorded by two investigators in order to blind associated variables in each FNE. We did not evaluate other potential adverse events besides BSI or transfer to ICU (e.g., culture negative sepsis) so we could focus on discrete FN-related outcomes. Because overall mortality among our patients was low $(2.3 \%)$, we lacked the power to perform subgroup analyses related to mortality as an outcome.

\section{Conclusion}

In this study, we derived and validated prediction rules for BSI and transfer to ICU in pediatric cancer patients who have FN. Children and adolescents with higher fever and hypotension at presentation are at increased risk of BSI and transfer to ICU. Having a prior BSI is an additional risk factor for developing a subsequent BSI. To the best of our knowledge, our study is one of the few done in the United States in last decade assessing the risk factors predictive of an adverse outcome in pediatric patients with FN. Our next step to facilitate antibiotic stewardship among pediatric cancer patients. The information gained from this study will help in formulating a risk prediction model that is easy to use, widely applicable, and clinically 
relevant. Prospective, external validation of this model is essential prior to implementation to risk stratify pediatric FN patients.

\section{Declarations}

\section{Competing Interests}

The authors declare that they have no competing interests.

The author(s) received no financial support for the research, authorship, and/or publication of this article.

\section{Corresponding author}

Correspondence to muayad Alali, MD

\section{References}

1. Ellis, M. Febrile neutropenia. Ann N Y Acad Sci, 1138, 329-50 (2008).

2. Freifeld, A. G. et al. Clinical practice guideline for the use of antimicrobial agents in neutropenic patients with cancer: 2010 update by the infectious diseases society of america. Clin Infect Dis, 52 (4), e56-93 (2011).

3. Lehrnbecher, T. et al. Guideline for the Management of Fever and Neutropenia in Children With Cancer and Hematopoietic Stem-Cell Transplantation Recipients: 2017 Update. J Clin Oncol, 35 (18), 2082-94 (2017).

4. te Poele, E. M., Tissing, W. J., Kamps, W. A. \& de Bont, E. S. Risk assessment in fever and neutropenia in children with cancer: What did we learn? Crit Rev Oncol Hematol, 72 (1), 45-55 (2009).

5. Oude Nijhuis, C. et al. Feasibility of withholding antibiotics in selected febrile neutropenic cancer patients. J Clin Oncol, 23 (30), 7437-44 (2005).

6. Klaassen, R. J., Goodman, T. R., Pham, B. \& Doyle, J. J. "Low-risk" prediction rule for pediatric oncology patients presenting with fever and neutropenia. J Clin Oncol, 18 (5), 1012-9 (2000).

7. Rackoff, W. R., Gonin, R., Robinson, C., Kreissman, S. G. \& Breitfeld, P. B. Predicting the risk of bacteremia in childen with fever and neutropenia. J Clin Oncol, 14 (3), 919-24 (1996).

8. Santolaya, M. E. et al. Admission clinical and laboratory factors associated with death in children with cancer during a febrile neutropenic episode. Pediatr Infect Dis J, 26 (9), 794-8 (2007).

9. Santolaya, M. E. et al. Prospective, multicenter evaluation of risk factors associated with invasive bacterial infection in children with cancer, neutropenia, and fever. J Clin Oncol, 19 (14), 3415-21 (2001).

10. Phillips, B., Wade, R., Stewart, L. A. \& Sutton, A. J. Systematic review and meta-analysis of the discriminatory performance of risk prediction rules in febrile neutropaenic episodes in children and young people. Eur J Cancer, 46 (16), 2950-64 (2010). 
11. Toll, D. B., Janssen, K. J., Vergouwe, Y. \& Moons, K. G. Validation, updating and impact of clinical prediction rules: a review. J Clin Epidemiol, 61 (11), 1085-94 (2008).

12. Ammann, R. A., Hirt, A., Luthy, A. R. \& Aebi, C. Identification of children presenting with fever in chemotherapy-induced neutropenia at low risk for severe bacterial infection. Med Pediatr Oncol, 41 (5), 436-43 (2003).

13. Ojha, R. P., Asdahl, P. H., Steyerberg, E. W. \& Schroeder, H. Predicting bacterial infections among pediatric cancer patients with febrile neutropenia: External validation of the PICNICC model.Pediatr Blood Cancer. 2018;65(4)

14. Phillips, R. S. et al. Risk stratification in febrile neutropenic episodes in adolescent/young adult patients with cancer. Eur J Cancer, 64, 101-6 (2016).

15. Hakim, H. et al. Risk prediction in pediatric cancer patients with fever and neutropenia. Pediatr Infect Dis J, 29 (1), 53-9 (2010).

16. Petty, L. A. et al. Repeated Blood Cultures in Pediatric Febrile Neutropenia: Would Following the Guidelines Alter the Outcome? Pediatr Blood Cancer, 63 (7), 1244-9 (2016).

17. Harris, P. A. et al. Research electronic data capture (REDCap)-a metadata-driven methodology and workflow process for providing translational research informatics support. J Biomed Inform, 42 (2), 377-81 (2009).

18. Phillips, R. S. et al. Predicting microbiologically defined infection in febrile neutropenic episodes in children: global individual participant data multivariable meta-analysis. Br J Cancer, 114 (12), e17 (2016).

19. Ammann, R. A. et al. Predicting adverse events in children with fever and chemotherapy-induced neutropenia: the prospective multicenter SPOG 2003 FN study. J Clin Oncol, 28 (12), 2008-14 (2010).

20. West, D. C. et al. Children with cancer, fever, and treatment-induced neutropenia: risk factors associated with illness requiring the administration of critical care therapies. Pediatr Emerg Care, 20 (2), 79-84 (2004).

21. Akova, M., Paesmans, M., Calandra, T., Viscoli, C. \& International Antimicrobial Therapy Group of the European. Organization for R, Treatment of C. A European Organization for Research and Treatment of Cancer-International Antimicrobial Therapy Group Study of secondary infections in febrile, neutropenic patients with cancer. Clin Infect Dis, 40 (2), 239-45 (2005).

22. Nucci, M. et al. Risk factors and attributable mortality associated with superinfections in neutropenic patients with cancer. Clin Infect Dis, 24 (4), 575-9 (1997).

\section{Tables}

\section{TABLE 1. Characteristics of FN episodes among pediatric cancer $(\mathrm{N}=505)$}




\begin{tabular}{|c|c|c|c|c|}
\hline & $\begin{array}{l}\text { All } \\
\text { Episodes } \\
(n=505)\end{array}$ & $\begin{array}{l}\text { FN episodes with positive } \\
\text { blood culture }(n=106)\end{array}$ & $\begin{array}{l}\text { FN episodes without } \\
\text { positive blood culture } \\
(n=399)\end{array}$ & $\begin{array}{l}\mathrm{P} \text { - } \\
\text { value }\end{array}$ \\
\hline Age, mean (SD) & $\begin{array}{l}11.08 \\
(6.4)\end{array}$ & $11.06(6.5)$ & $11.09(6.3)$ & 0.7 \\
\hline Female sex, n (\%) & $107(47)$ & $36(48)$ & $71(46)$ & 0.8 \\
\hline \multicolumn{5}{|l|}{$\begin{array}{l}\text { Cancer diagnosis, n } \\
(\%)\end{array}$} \\
\hline ALL/lymphoma & $218(43 \%)$ & $32(30 \%)$ & $186(46 \%)$ & 0.09 \\
\hline AML/mixed & $89(18 \%)$ & 37 (35\%) & $52(13 \%)$ & $<0.01$ \\
\hline leukemia & $69(14 \%)$ & $22(21 \%)$ & $47(13 \%)$ & 0.08 \\
\hline Neuroblastoma & $129(25 \%)$ & $15(14 \%)$ & $114(28 \%)$ & 0.07 \\
\hline \multicolumn{5}{|l|}{ Other solid tumors } \\
\hline \multicolumn{5}{|l|}{$\begin{array}{l}\text { Neutropenia >7 } \\
\text { days prior FN, } n \text { (\%) }\end{array}$} \\
\hline Yes & 346 (68) & $69(65)$ & 277 (69) & 0.8 \\
\hline No & $105(21)$ & $33(31)$ & $72(18)$ & \\
\hline Unknown & $54(11)$ & $4(4)$ & $50(13)$ & \\
\hline \multicolumn{5}{|l|}{ Prior BSI, n (\%) } \\
\hline Yes & $133(26)$ & $44(42) *$ & $89(22)$ & $<0.01$ \\
\hline No & $372(74)$ & $62(58)$ & 310 (78) & \\
\hline \multicolumn{5}{|l|}{$\begin{array}{l}\text { GI symptoms }{ }^{\star \star \star} n \\
(\%)\end{array}$} \\
\hline Yes & $173(34)$ & $36(34)$ & $137(34)$ & 0.9 \\
\hline No & $332(66)$ & $70(64)$ & $263(66)$ & \\
\hline \multicolumn{5}{|l|}{ Mucositis n (\%) } \\
\hline Yes & $111(22)$ & $23(21)$ & $88(22)$ & 0.9 \\
\hline No & 394 (78) & $83(79)$ & 312 (78) & \\
\hline \multicolumn{5}{|l|}{ VURI ** } \\
\hline Yes & 167 (33) & $19(18)^{\star}$ & $148(37)$ & 0.03 \\
\hline No & $268(53)$ & $72(68)$ & $196(49)$ & \\
\hline Unknown & $70(14)$ & $28(26)$ & $58(14)$ & \\
\hline Chills & & & & \\
\hline
\end{tabular}




\begin{tabular}{|c|c|c|c|c|}
\hline Yes & $28(6)$ & $13(12)^{\star}$ & $15(4)$ & 0.02 \\
\hline No & $477(94)$ & $93(88)$ & $384(96)$ & \\
\hline \multicolumn{5}{|l|}{ Hypotension } \\
\hline Yes & $89(18)$ & $39(36) *$ & $50(12.5)$ & $<0.01$ \\
\hline No & $416(82)$ & $75(70)$ & $341(86)$ & \\
\hline \multicolumn{5}{|l|}{$\begin{array}{l}\text { Temperature height } \\
\text { at presentation }\end{array}$} \\
\hline$>=39$ & $122(25)$ & $41(39) *$ & $81(20)$ & $<0.01$ \\
\hline$<39$ & $383(75)$ & $65(61)$ & $318(80)$ & \\
\hline \multicolumn{5}{|l|}{$\begin{array}{l}\text { Chemotherapy in } \\
\text { last } 2 \text { weeks }\end{array}$} \\
\hline Yes & $282(76)$ & 78(74) & $303(76)$ & 0.7 \\
\hline No & $124(34)$ & $28(26)$ & $96(24)$ & \\
\hline \multicolumn{5}{|l|}{$\begin{array}{l}\text { Inpatient (location } \\
\text { FN) }\end{array}$} \\
\hline Yes & $85(17)$ & $27(25)^{\star}$ & $59(15)$ & 0.02 \\
\hline No & $420(83)$ & $79(75)$ & 341 (85) & \\
\hline \multicolumn{5}{|l|}{$\mathrm{H} \times \mathrm{FN}>1$} \\
\hline $\begin{array}{l}\text { Yes ( } 2,3 \text { or } 4 \\
\text { episodes) }\end{array}$ & $311(61)$ & $81(76)^{*}$ & $230(57)$ & 0.01 \\
\hline No (0 or 1 episode) & 194 (39) & $29(27)$ & $165(41)$ & \\
\hline \multicolumn{5}{|l|}{ ALC, n (\%) } \\
\hline$<300$ & $156(31)$ & $44(41)^{*}$ & $112(28)$ & 0.012 \\
\hline$>300$ & $342(68)$ & $61(58)$ & $281(70)$ & \\
\hline Unknown & $7(1)$ & $1(1)$ & $6(2)$ & \\
\hline \multicolumn{5}{|l|}{ ANC, n (\%) } \\
\hline$<100$ & $362(72)$ & $78(74)$ & $284(71)$ & 0.713 \\
\hline$>100$ & $143(28)$ & $28(26)$ & $115(29)$ & \\
\hline \multicolumn{5}{|l|}{ AMC n (\%) } \\
\hline$<100$ & 389 (77) & $84(79)$ & $304(76)$ & 0.68 \\
\hline$>100$ & $105(21)$ & $19(18)$ & $86(22)$ & \\
\hline Unknown & $12(2)$ & $3(3)$ & $9(2)$ & \\
\hline
\end{tabular}




\begin{tabular}{|lllll|}
\hline Platelet & & & & \\
\hline$>50$ & $308(61)$ & $226(57)^{\star}$ & $82(77)$ & 0.01 \\
\hline $\mathrm{Hb}<7$ & $197(39)$ & $173(43)$ & $24(23)$ & \\
\hline Yes & & & & \\
\hline No & $103(20)$ & $29(27)$ & $74(18)$ & \\
\hline Prior GCSF & $402(80)$ & $77(73)$ & $325(82)$ & 0.158 \\
\hline Yes & $66(13)$ & $57(14)$ & $9(9)$ & $<0.01$ \\
\hline No & $439(87)$ & $342(86)$ & $97(91)$ & \\
\hline $\begin{array}{l}\text { Admitted to the } \\
\text { PICU, } n(\%)\end{array}$ & $54(11)$ & $24(23)^{\star}$ & $30(8)$ & \\
\hline
\end{tabular}

${ }^{*} \mathrm{P}<0.05$ compared to patient admission that did not develop positive blood culture

** VURI viral upper respiratory infection documented by RVP

***includes subjective symptoms such as vomiting, diarrhea, or abdomen pain

TABLE 2. Characteristics variables and outcomes in FNEs among derivation and validation cohorts $(\mathrm{N}=505)$ 


\begin{tabular}{|c|c|c|c|}
\hline & $\begin{array}{l}\text { All Episodes } \\
(n=505) \mathrm{N} \\
(\%)\end{array}$ & $\begin{array}{l}\text { Derivation cohort } \\
(2009-2014, n=343 \\
[68 \%])\end{array}$ & $\begin{array}{l}\text { Validation cohort } \\
(2015-2016), \mathrm{n}= \\
162[32 \%])\end{array}$ \\
\hline Age, mean (SD) & $11.08(6.4)$ & $10.16(5.8)$ & $12.59(6.8)$ \\
\hline Female sex & $107(47)$ & $159(46)$ & $69(42)$ \\
\hline \multicolumn{4}{|l|}{ Cancer diagnosis } \\
\hline ALL/lymphoma & $218(43 \%)$ & $149(44 \%)$ & $69(41 \%)$ \\
\hline AML/mixed leukemia & $89(18 \%)$ & $54(16 \%)$ & $35(21 \%)$ \\
\hline Neuroblastoma & $69(14 \%)$ & $51(15 \%)$ & $18(11 \%)$ \\
\hline Other solid tumors & $129(25 \%)$ & $89(26 \%)$ & $40(24 \%)$ \\
\hline Neutropenia $>7$ days prior FN & $346(68)$ & $221(70)$ & $125(75)$ \\
\hline Prior BSI in last 12 months & $133(26)$ & $83(24)$ & $50(30)$ \\
\hline GI symptoms n (\%) & $173(34)$ & $125(36)$ & $48(30)$ \\
\hline Mucositis n (\%) & $111(22)$ & $81(24)$ & $30(18)$ \\
\hline VURI & $167(33)$ & 109(31) & $58(35)$ \\
\hline Chills & $28(6)$ & $18(5)$ & $10(6)$ \\
\hline Hypotension & $89(18)$ & $68(20)$ & $21(13)$ \\
\hline $\begin{array}{l}\text { Temperature }>39 \text { at } \\
\text { presentation }\end{array}$ & $122(25)$ & $91(26)$ & $31(19)$ \\
\hline Chemotherapy in last 2 weeks & $282(76)$ & $198(57)$ & $84(52)$ \\
\hline Inpatient (location FN) & $85(17)$ & $52(15)$ & $33(20)$ \\
\hline $\mathrm{Hx} F \mathrm{~F}>1$ & $311(61)$ & $201(58)$ & $110(68)$ \\
\hline ALC <300, n (\%) & $156(31)$ & $96(28)$ & $60(37)$ \\
\hline ANC<100, n (\%) & 362 (72) & $239(70)$ & $123(76)$ \\
\hline AMC < 100 n (\%) & 389 (77) & $251(74)$ & $138(85)$ \\
\hline Platelet $<50$ & 308 (61) & 203 (59) & 105 (64) \\
\hline $\mathrm{Hb}<7$ & $103(20)$ & $77(22)$ & $26(16)$ \\
\hline Prior GCSF & $66(13)$ & $41(12)$ & $25(15)$ \\
\hline BSI & $106(21)$ & $66(19)$ & $40(24)$ \\
\hline Admitted to the PICU, n (\%) & $54(11)$ & $35(10)$ & $19(12)$ \\
\hline
\end{tabular}


Table 3. Statical Performance of 3 prediction models for BSI and TIC

\begin{tabular}{|c|c|c|c|c|c|c|c|c|}
\hline & Threshold & $\begin{array}{l}\text { Sensitivity } \\
\%( \pm \\
95 \% \mathrm{Cl})\end{array}$ & $\begin{array}{l}\text { Specificity } \\
\%( \pm \\
95 \% \mathrm{Cl})\end{array}$ & $\begin{array}{l}\text { PPV \% } \\
( \pm+ \pm \\
95 \% \mathrm{Cl})\end{array}$ & $\begin{array}{l}\text { NPV \% } \\
(\stackrel{ \pm}{95 \% \mathrm{Cl})}\end{array}$ & $\begin{array}{l}\text { LR+ } \\
(\mathrm{HR})\end{array}$ & $\begin{array}{l}\text { LR- } \\
(\mathrm{LR})\end{array}$ & $\begin{array}{l}\text { AUC }(95 \% \\
\text { CI) }\end{array}$ \\
\hline \multicolumn{9}{|l|}{ BSI } \\
\hline $\begin{array}{l}\text { Random } \\
\text { Forest }\end{array}$ & 0.056 & $\begin{array}{l}81(68- \\
92)^{\star}\end{array}$ & $\begin{array}{l}77(65- \\
89)^{\star}\end{array}$ & $\begin{array}{l}51(43- \\
66)\end{array}$ & $\begin{array}{l}91(82- \\
98)^{\star}\end{array}$ & $3.5^{\star}$ & 0.24 & $\begin{array}{l}0.79 \\
(0.71- \\
0.85)^{\star}\end{array}$ \\
\hline $\begin{array}{l}\text { Logistic } \\
\text { Regression }\end{array}$ & 0.06 & $84)^{73(63-}$ & $70(61-80)$ & $\begin{array}{l}46(55- \\
38)\end{array}$ & $\begin{array}{l}86(78- \\
90)\end{array}$ & 2.4 & 0.38 & $\begin{array}{l}0.65 \\
(0.53 \\
0.76)\end{array}$ \\
\hline Hakim & - & $68(62-74)$ & $\begin{array}{l}62(54- \\
71)\end{array}$ & $\begin{array}{l}40(36- \\
48)\end{array}$ & $\begin{array}{l}79(71- \\
87)\end{array}$ & 1.7 & 0.61 & $\begin{array}{l}0.66 \\
(0.56 \\
0.77)\end{array}$ \\
\hline \multicolumn{9}{|l|}{ TIC } \\
\hline $\begin{array}{l}\text { Random } \\
\text { Forest }\end{array}$ & 0.049 & $\begin{array}{l}89(78- \\
97)^{\star}\end{array}$ & $\begin{array}{l}87(80- \\
95)^{\star}\end{array}$ & $\begin{array}{l}56(47- \\
64)\end{array}$ & $\begin{array}{l}97(92- \\
99)^{*}\end{array}$ & $6.8^{*}$ & $0.12^{*}$ & $\begin{array}{l}0.88 \\
(0.76 \\
0.99)^{*}\end{array}$ \\
\hline $\begin{array}{l}\text { Logistic } \\
\text { Regression }\end{array}$ & 0.053 & 81 (71-90) & $83(77-88)$ & $\begin{array}{l}46(39- \\
53)\end{array}$ & $\begin{array}{l}92(85- \\
97)\end{array}$ & 4.7 & 0.22 & $\begin{array}{l}0.76 \\
(0.60 \\
0.92)\end{array}$ \\
\hline Hakim & - & $71(62-80)$ & 72 (68-79) & $\begin{array}{l}35(27- \\
44)\end{array}$ & $\begin{array}{l}80(73- \\
86)\end{array}$ & 2.5 & 0.4 & $\begin{array}{l}0.65 \\
(0.50 \\
0.80)\end{array}$ \\
\hline
\end{tabular}

*P $<0.05$ compared to the Hakim model

\section{Figures}




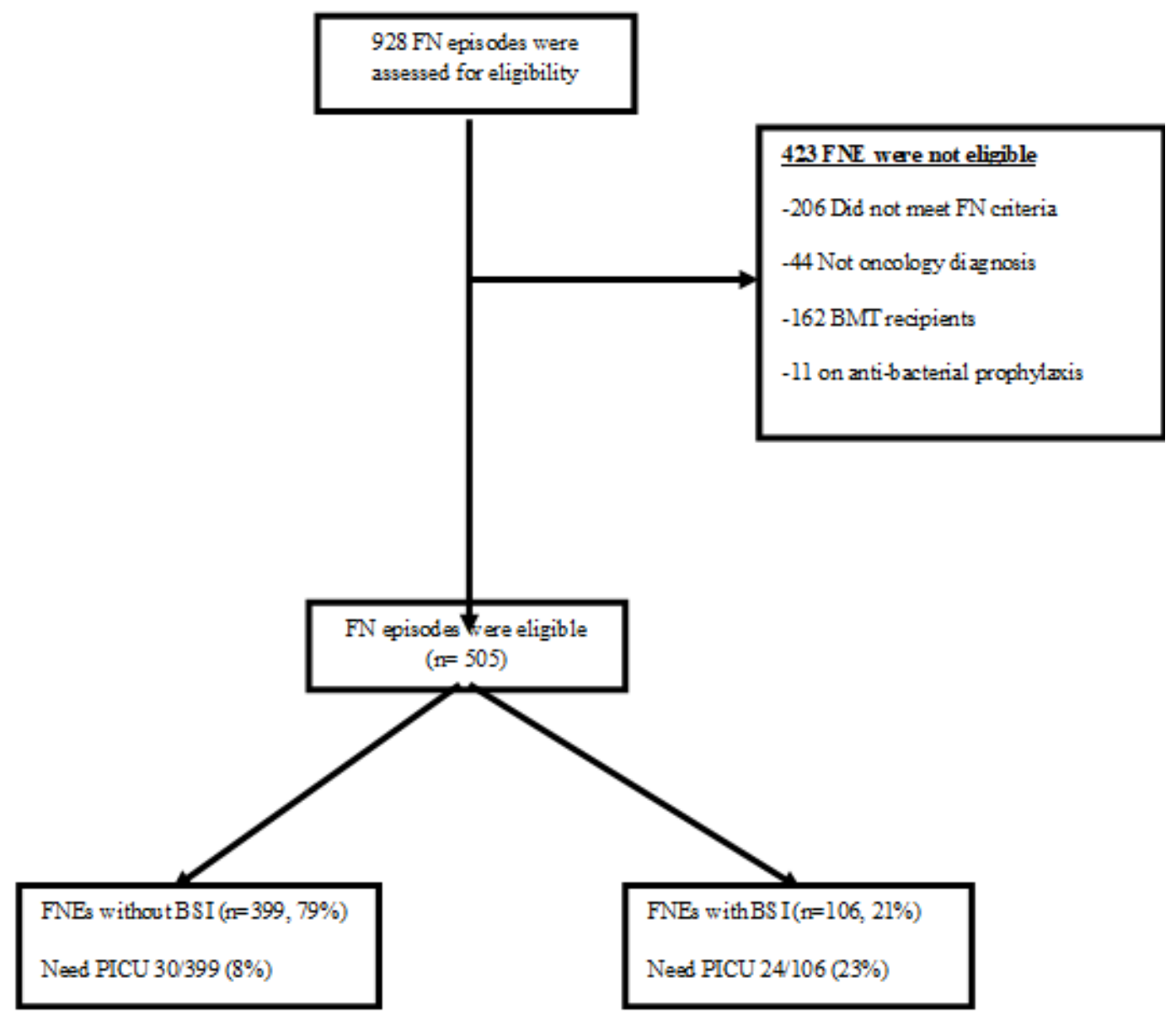

Figure 1

Study flow diagram. Febrile neutropenia (FN) with and without BSI and need to PICU. FNE. Febrile neutropenia episodes, BSI : blood stream infection. PICU: pediatric intensive care, BMT: bone marrow transplant 


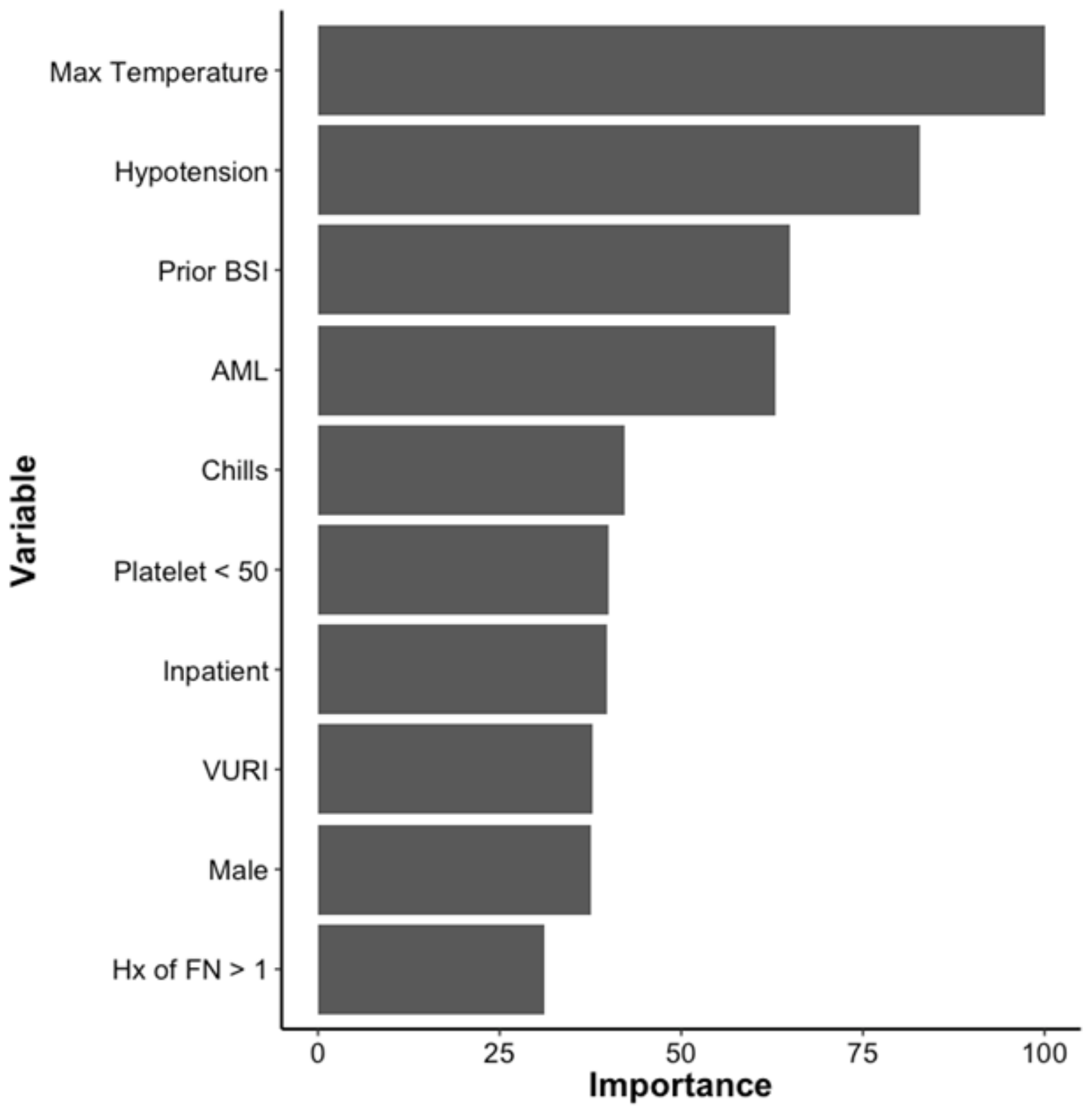

\section{Figure 2}

depicts a list of variables important to the prediction of bactremia using the Random Forest model. Temperature height and hypotension recorded at time of presentation of FN episode, prior positive blood culture, and AML diagnosis were variables that contributed the most to BSI prediction. 


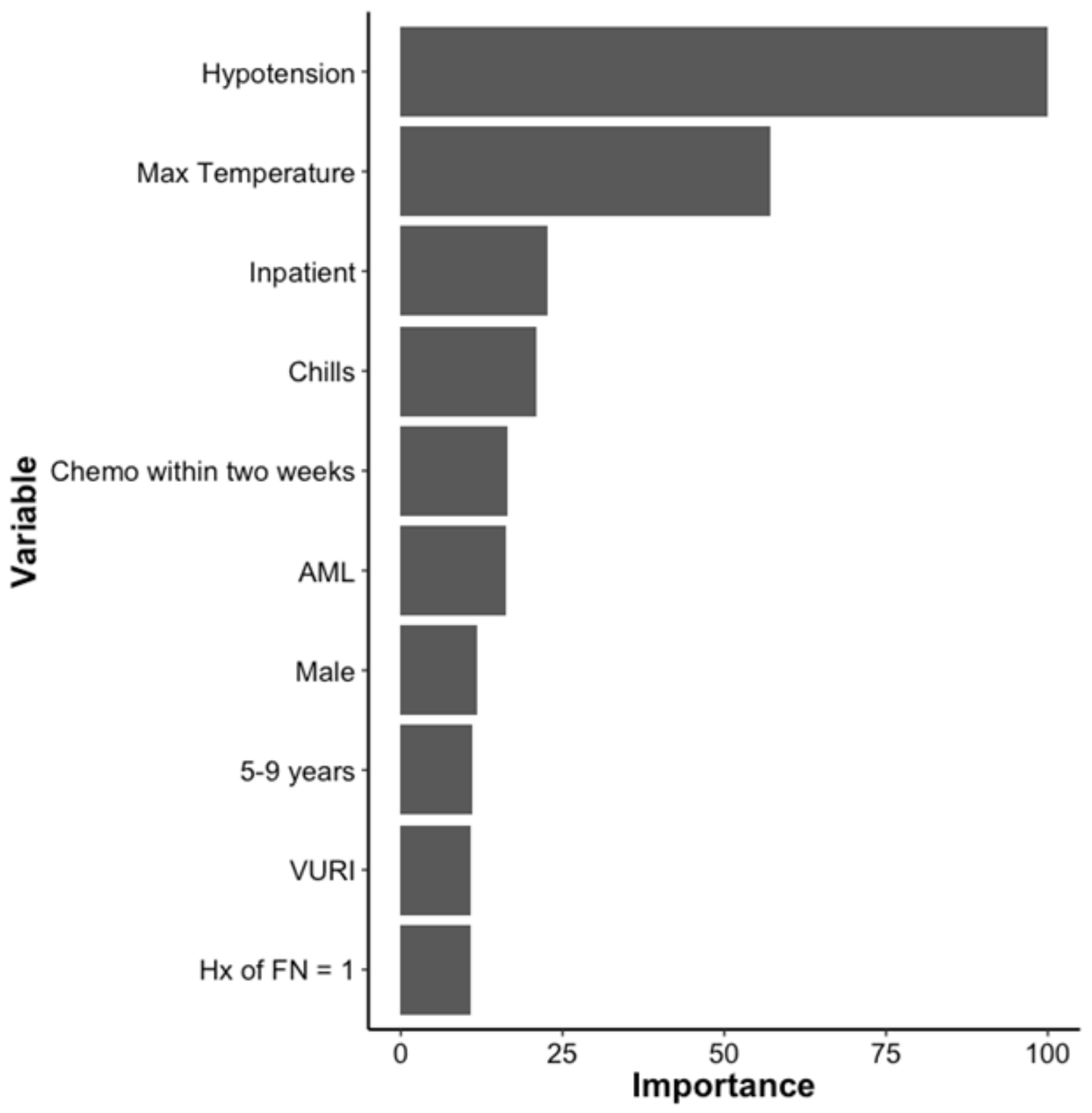

\section{Figure 3}

depicts a list of variables important to the prediction of PICU admission with resampling of the multivariate analysis. The maximum temperature and hypotension recorded at time of presentation of FN episode were the most important variables for predicting transfer to PICU. 


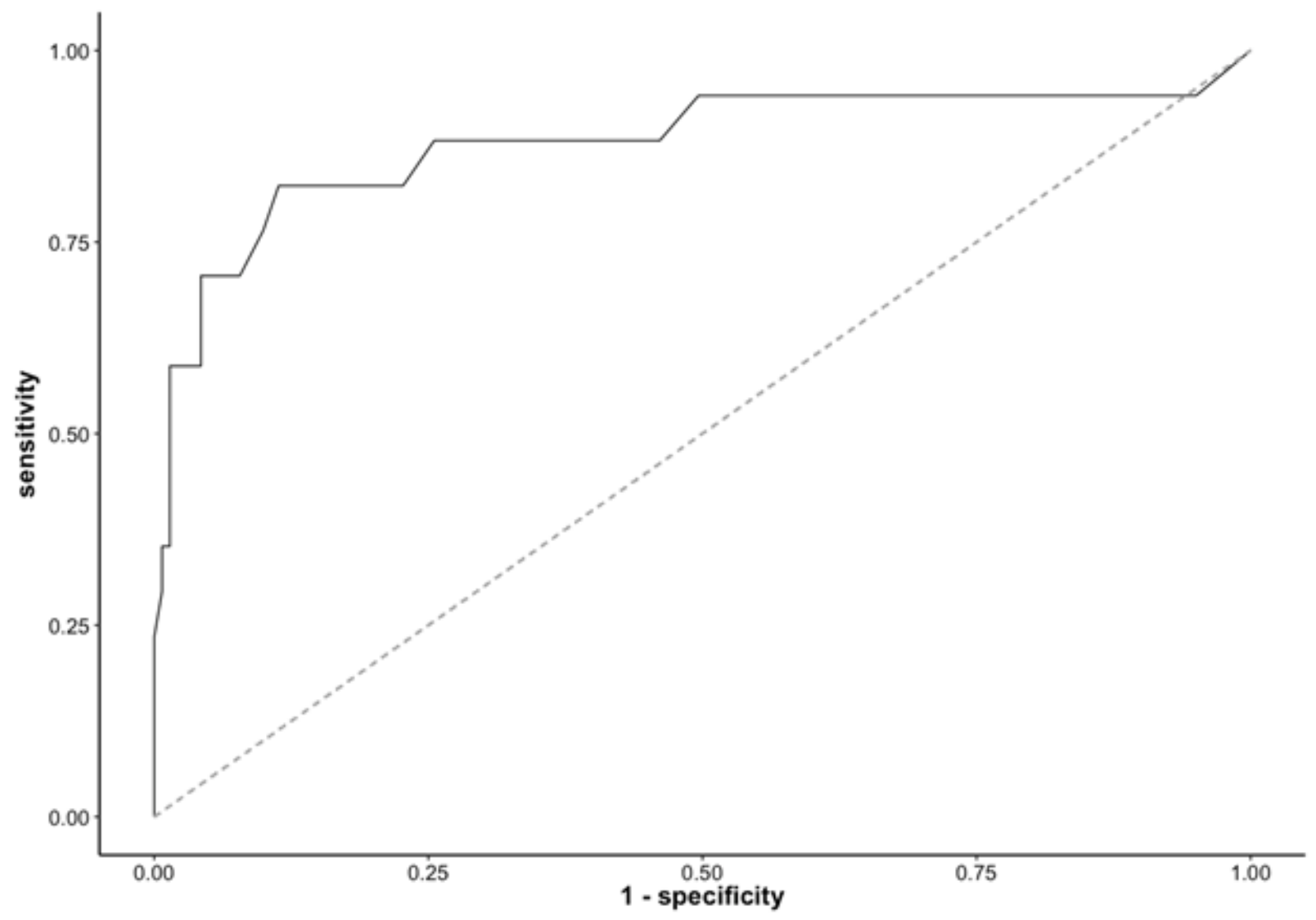

Figure 4

Receiver Operating Characteristic Curve for Random Forest (RF) model in BSI prediction (AUC 0.79)

\section{Supplementary Files}

This is a list of supplementary files associated with this preprint. Click to download.

- Supplementaltables2.docx 